\title{
Ogroženost zaradi naravnih procesov kot strukturni element slovenskih pokrajin
}

\author{
Karel Natek \\ Dr., Oddelek za geografijo, Filozofska fakulteta, Univerza v Ljubljani, \\ Aškerčeva 2,1000 Ljubljana, Slovenija \\ e-mail: karel.natek@guest.arnes.si
}

\section{Izvleček}

Preučevanje naravnih nesreč je $v$ zadnjih desetletjih eden najpomembnejših vidikov aplikacije fizične geografije $v$ Sloveniji. Ogroženost zaradi tovrstnih naravnih dogodkov je namreč na različne načine prisotna $v$ vsaki kulturni pokrajini, in sicer kot njihovi neposredni učinki in konkretni načini varovanja pred njimi, kot izogibanje ogroženim območjem in tudi kot napačni posegi v prostor. Vse to so pomembne geografske teme, s katerimi se bo morala geografija v prihodnje še intenzivneje ukvarjati, poleg tega pa bo potrebno upoštevati tudi subjektivno zaznavanje ogroženosti zaradi naravnih nesreč kot pomembno izhodišče nadaljnjih posegov $v$ ogrožena območja, na katerih delujejo potencialno škodljivi ali nevarni naravni procesi.

Ključne besede: geografija, naravne nesreče, kulturna pokrajina, ogroženost.

\section{Human vulnerability due to natural processes as a constituent element of slovenian regions}

\begin{abstract}
The study of natural hazards since the 1950s is considered as one of the most important contributions of physical geography to the application of geographical knowledge in Slovenia. The threat of destructive natural events and significant degree of vulnerability are constituent parts of every cultural landscape, and can be recognized as immediate effects of natural processes, as practical countermeasures to prevent damages, as keeping off the most hazardous areas and, also, as unsuitable acts or wrong interventions into the geographical space. These elements are presented as important topics of geographical research in the near future, together with the study of subjective, personal, perception of vulnerability due to natural hazards, which is one of the key starting-points for future dealing with areas, where the potentially damaging or dangerous natural processes are in action.
\end{abstract}

Key words: geography, natural hazards, cultural landscape, human vulnerability 


\section{UVOD}

Preučevanje slovenskih pokrajin z vidika ogroženosti zaradi naravnih nesreč je bilo $\mathrm{v}$ zadnjih nekaj desetletjih zagotovo eden najpomembnejših prispevkov fizične geografije $\mathrm{k}$ aplikaciji geografije v Sloveniji. Vse do 2. svetovne vojne in še po njej so se ti dogodki prikazovali skoraj izključno v obliki kratkih časopisnih notic ali poljudnih opisov. Izjema je ljubljanski potres 14. aprila 1895, ki je bil mdr. neposredni povod za ustanovitev stalne potresne komisije za celotno območje takratne avstro-ogrske monarhije pri Akademiji znanosti na Dunaju (Erdbeben-Kommission, ustanovljena 25. aprila 1895; Ribarič, 1994, 85), 18. septembra 1897 pa je v kleti realne gimnazije v Ljubljani začela delovati seizmološka postaja, ki jo je izdelal in precej časa vodil Albin Belar, začetnik slovenske seizmologije (Ribarič, 1994, 88).

Novoustanovljeni Inštitut za geografijo pri Slovenski akademiji znanosti in umetnosti (današnji Geografski inštitut Antona Melika ZRC SAZU; 1948) si je takoj na začetku delovanja postavil kot eno pomembnih nalog tudi preučevanje naravnih nesreč. Ob veliki poplavi junija 1954 v Celju in okolici je večja skupina geografov in drugih strokovnjakov pod vodstvom Antona Melika (Ivan Gams, Slavko Marolt, Anton Sore, Drago Predan, Silva Arlič, Drago Rebernik, Marjan Žagar, Emil Kolenik, Mara Radinja, Zdenka Zupančič in Milan Šifrer) zelo podrobno preučila vzroke in posledice te ujme, kar lahko štejemo za prvo sistematično študijo naravnih nesreč v Sloveniji (Melik, 1954). V naslednjih letih je $\mathrm{v}$ geografskih in drugih publikacijah izšla vrsta temeljitih študij o poplavnih področjih, vremenskih ujmah, zemeljskih plazovih, potresih in drugih naravnih nesrečah, predvsem v Geografskem zborniku, Geografskem vestniku in nalašč za to tematiko ustanovljeni strokovni reviji Ujma (prva številka je izšla 1987).

Eden od pomembnih vrhuncev geografskega preučevanja naravnih nesreč je bilo leto 1983, ko sta v Ljubljani drug za drugim potekala kar dva pomembna znanstvena sestanka na to temo: jugoslovanski simpozij o metodologiji geografskega preučevanja naravnih nesreč (prispevki so bili objavljeni v zborniku Naravne nesreče v Jugoslaviji, 1983) in slovenski simpozij o naravnih nesrečah v Sloveniji (prispevki objavljeni v zborniku Naravne nesreče v Sloveniji, 1983).

$\mathrm{S}$ temi in $\mathrm{v}$ zadnjih letih vse številnejšimi in bolj poglobljenimi preučevanji smo geografi, skupaj s strokovnjaki iz drugih strok, pomembno obogatili naše védenje o delovanju naravnih nesreč, ogroženosti zaradi njih ter tveganjih, ki smo jim v vsakdanjem življenju in posebej pri delovanju v konkretnem prostoru venomer izpostavljeni. Ta spoznanja so sicer v določeni meri vgrajena $\mathrm{v}$ obstoječi sistem zaščite in reševanja ter deloma tudi v nastajajoči 
novi prostorski plan Slovenije, vendar nas kljub temu vsak nov tovrstni dogodek/ proces (naravna nesreča) preseneti in za kratek čas vzbudi strah pred 'kruto naravo', ki se 'poigrava' s človeškimi življenji.

Slika 1: Poplava Krke pri Drami julija 1999; sredi slike je streha nad izkopaninami srednjeveškega trga Gutenwerth, levo za njo cerkev sv. Miklavža na nizki vzpetini.

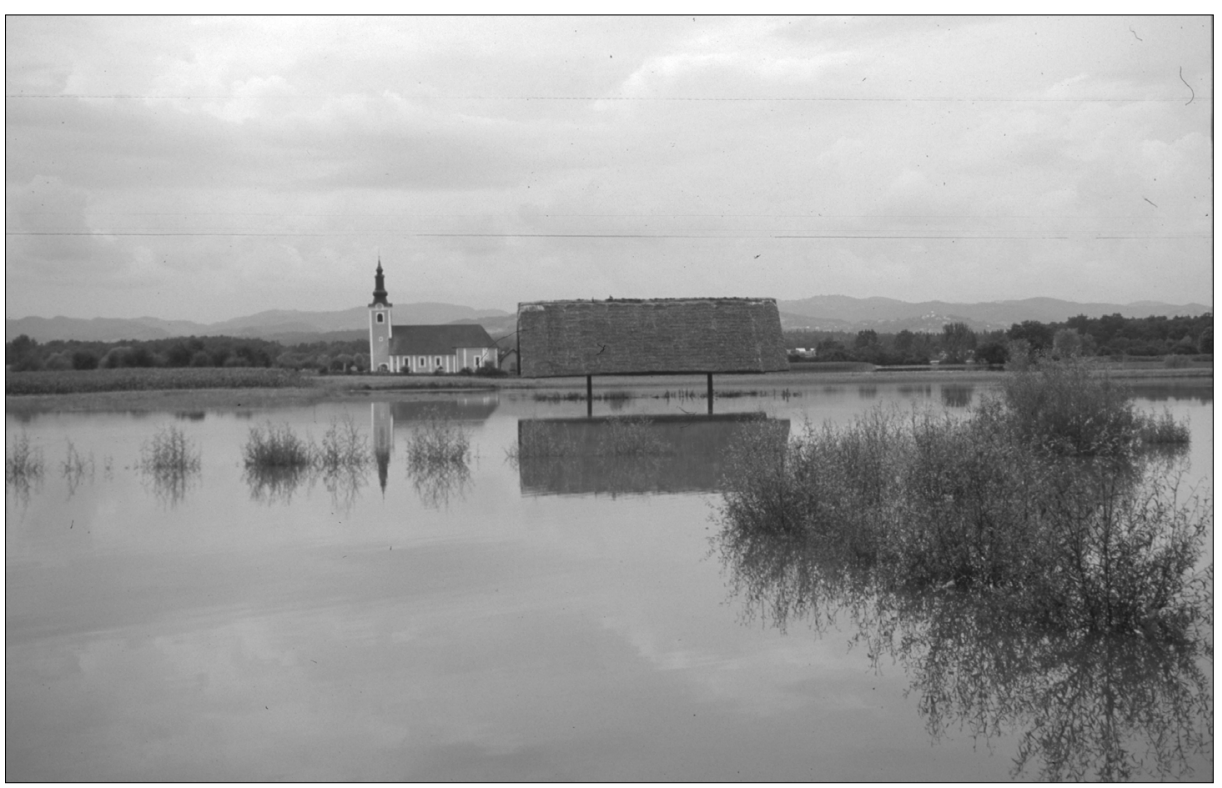

\section{OGROŽENOST ZARADI NARAVNIH NESREČ KOT POKRAJINSKI ELEMENT}

Eden od ključnih rezultatov geografskih preučevanj ogroženosti je ugotovitev, da so takšni dogodki/procesi (naravne nesreče) sestavni deli naravnega dogajanja, ki ga človek praviloma ne more preprečiti, temveč se mu mora na čim ustreznejše načine prilagoditi. Te prilagoditve so najrazličnejših vrst, od potresno varne gradnje in suši ali pozebi prilagojenih posevkov do pravilne lokacije objektov. Nas geografe zanimajo predvsem tiste prilagoditve, ki "pomagajo ustvarjati podobo pokrajine" (Gams, 1983, 13).

S temi 'pokrajinotvornimi' prilagoditvami postane ogroženost zaradi naravnih dogodkov (nesreč) pomembna sestavina vsake kulturne pokrajine, kajti 
$\mathrm{v}$ t.i. naravnih pokrajinah, kjer človek ni prisoten, naravnih nesreč ni, tam so zgolj naravni procesi.

V kulturni pokrajini lahko ugotovimo naslednje štiri sestavine ogroženosti:

1. Neposredni učinki naravnih dogodkov/procesov (podorne skale, starejši zemeljski plazovi, hudourniški nanosi idr.). Tovrstne ostanke preteklosti naravni procesi $\mathrm{v}$ teku časa počasi preoblikujejo, tako da jih je vse težje identificirati in, posebno $\mathrm{v}$ primeru redkih dogodkov, sčasoma postanejo v pokrajini bolj ali manj neopazni. Velika zemeljska plazova, ki sta se sprožila ob poplavah novembra 1990 v vasi Raduha v dolini Savinje pod Lučami in v dolini Lučnice, sta nas sicer precej presenetila, a se je pozneje izkazalo, da se je plaz v Raduhi odtrgal na popolnoma istem mestu kot že pred stoletji; spregledali smo celo zelo zgovorno ledinsko ime Pekel za težko prehoden svet nekdanjega plazu (Natek, 1991, 62-63).

Slika 2: Gruščnati tok izpod Mangarta je 17. novembra 2000 odnesel del vasi Log pod Mangartom in na debelo zasul ravnico ob Koritnici.

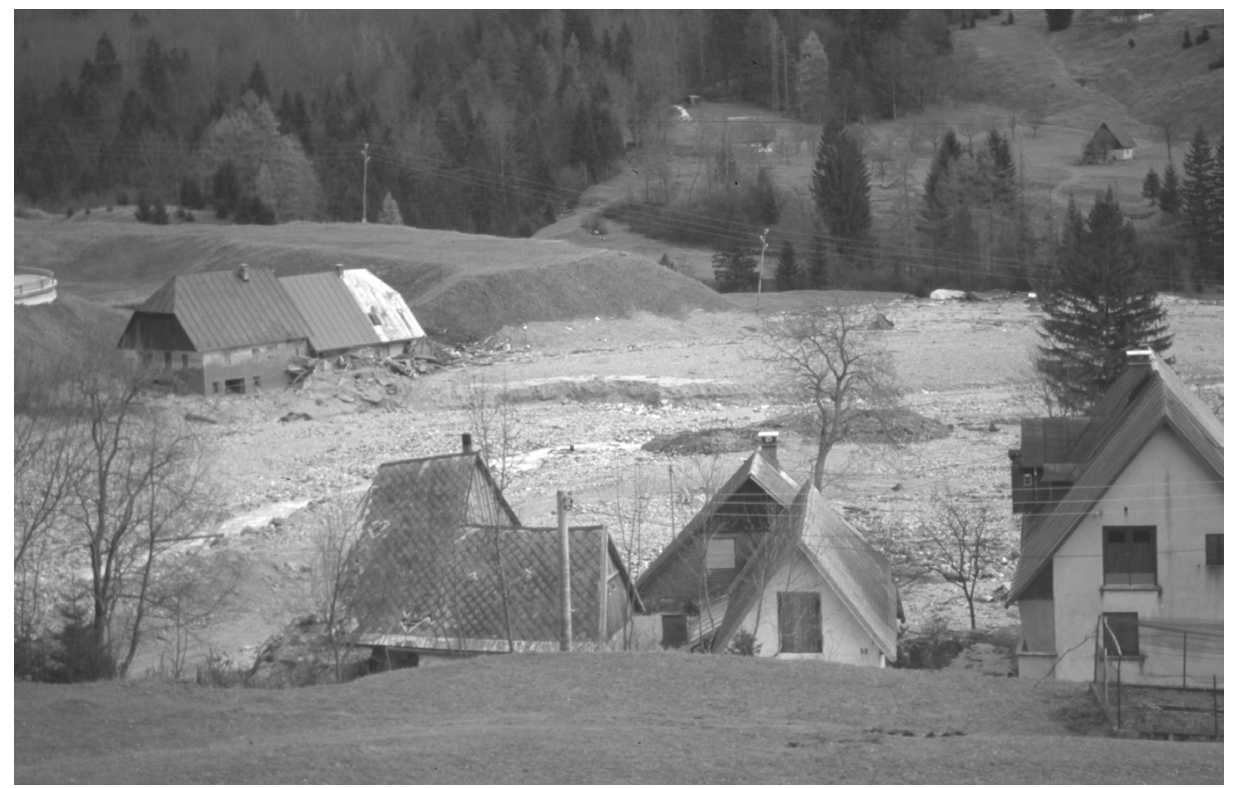

Zanimiv pokazatelj geomorfnega dogajanja so vršaji v dolinah našega hribovskega in gričevnatega sveta. Nastajajo kot rezultat hudourniškega nasipanja ob močnejših nalivih in so zaradi tega nevarni, a so ob splošnem pomanjkanju 
ravnega sveta izjemno pomembni za agrarno poselitev. Pri tem je zelo pomembno ločevati med danes neaktivnimi periglacialnimi vršaji iz zadnje ledene dobe, v katere so potoki pozneje vrezali globoke struge (Meze, 1966; Šifrer, 1974), in praviloma manjšimi recentnimi vršaji, ki še vedno nastajajo ob izstopih ozkih grap v glavne doline.

2. Nekateri pokrajinski elementi kažejo, da se človek zaveda nevarnosti naravnih dogodkov in se ogroženim območjem izogiba. V visokogorskem svetu se npr. vsako zimo sprožijo tisoči snežnih plazov, vendar le redko prizadenejo dolinska naselja, saj so ljudje iz lastnih izkušenj ugotovili, kje se plazovi prožijo in do kam sežejo. Kljub temu se zgodi, da ob izjemnih snežnih padavinah nastanejo plazovi tudi izven nevarnih območij ali pa postanejo izjemno veliki in povzročijo hude katastrofe. Pri nas se je to zgodilo v Zgornjem Posočju ob izjemnih snežnih padavinah februarja 1952, ko so snežni plazovi porušili 11 stanovanjskih hiš in je umrlo 15 ljudi; najhuje je bilo v Borjani na južnem vznožju (Kobariškega) Stola (Gams, 1955). V sosednji Avstriji se je podobna katastrofa zgodila 23. in 24. februarja 2000 v vasi Galtür na Tirolskem (33 mrtvih).

$\mathrm{Na}$ nekaterih slovenskih poplavnih območjih je prav presenetljivo, kako tesno ob meji območij rednih poplav so nameščena naselja, kar kaže na velik pomen izkustvene metode pri ustvarjanju kulturne pokrajine (Radinja, 1983, 22). Določena težava je nastala, ko se je v nekaterih poplavnih območjih obseg poplav po nastanku teh naselij povečal, zelo verjetno zaradi intenzivnega krčenja gozdov in poseljevanja hribovitih območij, kar je sprožilo povečano denudacijo in posledično močnejše nasipanje $\mathrm{v}$ poplavnih ravnicah, npr. ob spodnjem toku Krke pod Otočcem (Šifrer-Lovrenčak-Natek, 1981).

Seveda pa je položaj teh naselij povsem drugačen glede na izjemne poplave, vendar gre pri tem za "svojevrstno prilagajanje (tveganje) človeka komaj še ustreznim naravnim osnovam" (Radinja, 1983, 22). Pri tem so ljudje že od nekdaj primerjali tveganja in potencialne koristi in so $\mathrm{v}$ prilagoditve naravnim danostim vkalkulirali tudi škode zaradi izjemnih dogodkov. Na podoben način se je $\mathrm{v}$ rabi tal izoblikovala tudi spodnja meja vinogradov in občutljivih vrst sadnega drevja v t.i. termalnem pasu nad dolinskim dnom (Gams, 1996).

Veliko težje je ugotoviti ogroženost zaradi takšnih ali drugačnih naravnih dogodkov, kadar se znajdemo v nepoznani pokrajini ali ko posegamo v dotlej neposeljena območja. Zaradi premajhnega poznavanja naravnih razmer je npr. snežni plaz 30.3.1975 uničil C postajo novozgrajene žičnice na Kanin. Čeprav se ljudje dotlej pozimi na tem območju niso veliko zadrževali, so domačini vedeli, da je predvidena lokacija nevarna zaradi plazov, a jih načrtovalci niso hoteli poslušati (Mulej, 1994, 100). 
3. V mnogih pokrajinah pri nas in po svetu so se ljudje morali na zelo različne načine zavarovati pred dogodki, ki so neposredno ogrožali njihova življenja ali premoženje, saj absolutno varnih območij ni nikjer na Zemlji ali pa niso imeli izbire. Že v davni preteklosti so ljudje poznali mnoge načine varovanja, npr. kolišča na poplavnih območjih in $\mathrm{v}$ močvirjih ali umetno nasute gričke ob obali Severnega morja (v Friziji imenovani warft, v Holandiji terp, na spodnjem Saškem wierde, v Schleswig-Holsteinu wurt, na Danskem vaerft).

$Z$ razvojem znanosti in tehnike se je nabor možnih ukrepov za zaščito pred naravnimi dogodki/procesi silovito povečal, to pa je poleg velikih koristi imelo tudi negativni učinek: $\mathrm{z}$ uvajanjem novih metod zaščite se je pritisk na ogrožena območja silovito povečal, pri ljudeh pa se je razvil pretirani občutek varnosti.

Občutno zmanjšanje števila smrtnih žrtev zaradi naravnih nesreč zlasti $\mathrm{v}$ gospodarsko razvitejših državah gre $\mathrm{v}$ veliki meri ravno na račun neposrednih zaščitnih ukrepov pred temi dogodki. Nekateri ukrepi so v pokrajini zelo očitni, tako vidno kot tudi funkcionalno (npr. Protipoplavni nasipi, večnamenski vodni zadrževalniki, protipoplavna zavetišča v Bangladešu, project Delta na Nizozemskem), drugi na prvi pogled komajda opazni (npr. Potresno varno grajene stavbe, podzemna zavetja pred tornadi, vodotesne kleti na poplavnem območju). Med slednje moremo prištevati tudi različne sisteme za opazovanje, zgodnje obveščanje, zaščito in reševanje, ki so pri nekaterih vrstah nesreč zelo učinkoviti (npr. Pri tropskih viharjih, tornadih, tsunamijih), pri drugih pa smo bolj ali manj nebogljeni (npr. Pri potresih ali ognjeniških izbruhih).

4. $\mathrm{K}$ boljšemu poznavanju naravnih procesov in njihovemu vplivu na ljudi lahko zelo veliko prispevajo tudi preučevanja napačnih posegov v tvegana območja. To je geografska tematika par excellence, saj se s pokrajinskimi učinki naravnih nesreč "na prepričljiv način kaže osrednja problematika geografije, nanašajoč se na spreminjajoče se odnose med naravo in družbo" (Radinja, 1983, 17). Hkrati s temi preučevanji "vzdržujemo živo zavest o ogroženosti ozemlja in razširjamo znanje, kakšno je naustreznejše ravnanje $\mathrm{v}$ primeru katastrofe" (Gams, 1983, 9). Številne geografske in druge študije naravnih nesreč so polne ugotovitev, kako so napačni posegi ali poseganje na neprava mesta ali na neprimeren način prispevali k povzročeni škodi.

Naj navedem samo nekaj primerov: regulacija Savinje in izgradnja protipoplavnih nasipov tik ob njeni strugi je povzročila poglabljanje rečne struge na odseku med Letušem in izlivom Bolske pod Dolenjo vasjo, zaradi česar je reka 1973 spodjedla most na glavni cesti Celje-Ljubljana. To vrezovanje je povzročilo tudi dvig rečne struge $\mathrm{v}$ Laškem (posledica so bile katastrofalne poplave 4. in 5. novembra 1998), veliko hitrejši dotok poplavnih voda na sotočje v Celju, posledično pa tudi širjenje naselij na poplavno območje. 
Slika 3: Očem skrita plošča z označeno višino poplavne vode 1926 na trasformatorju ob Tržaški cesti na Viču (Ljubljana).

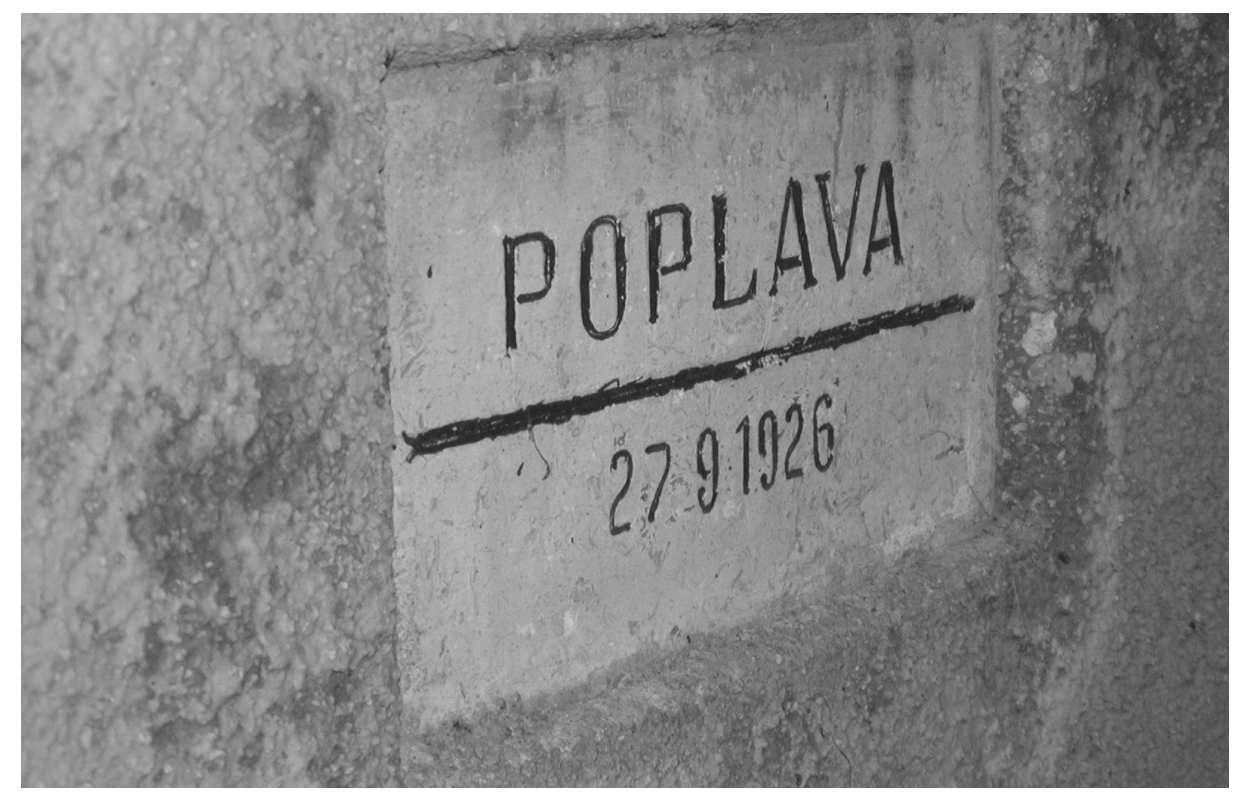

Do porušitve številnih mostov na Savinji in njenih pritokih ob poplavi 1. novembra 1990 je prišlo zato, ker se je na opornikih nabralo vejevje in drevje, ki so ga s sabo prinašali hudourniki. Namesto dodatnih posegov, $\mathrm{s}$ katerimi bi (neuspešno) poskušali zmanjšati dotok tega materiala v poplavne vode, je skupina geografov takrat predlagala gradnjo novih mostov brez opornikov $\mathrm{v}$ hudourniških strugah, kar je $\mathrm{z}$ današnjo tehnologijo gradnje zelo lahko izvedljivo.

Na vseh pobočjih delujejo najrazličnejši pobočni procesi, ki se poskušajo neprestano prilagajati danim geološkim, geomorfološkim, klimatskim in drugim okoliščinam. $\mathrm{V}$ povsem naravnih razmerah so pobočja večinoma $\mathrm{v}$ dinamičnem ravnovesju, ki ga lahko človek tudi z majhnimi posegi hitro poruši. Ob poletnem neurju 3. in 4. julija 1989 se je v Halozah na $106 \mathrm{~km}^{2}$ velikem območju utrgalo okrog 5000 zemeljskih plazov, od katerih jih je bilo več kot $45 \%$ neposredno povezanih s človekovimi posegi v pobočje (ceste ali poljske poti, njive in vinogradi; Natek, 1990, 14).

Ljudje so se od nekdaj poskušali čim bolj prilagoditi naravnim razmeram v okolju, v katerem so morali tako ali drugače preživeti. Do spoznanj o tem so prišli z (neznanstvenim!?) opazovanjem narave, neštetimi poskusi tolmačenja in napovedovanja nadaljnjega poteka naravnih procesov ter uporabo teh spo- 
znanj v praksi. Ta v večini primerov ni temeljila na naključnih poskusih in napakah, kot se prepogosto zmotno misli, temveč na znanju, ki ga je vsaka generacija podedovala od prejšnjih in nato sama še dopolnila. To znanje je sicer bilo in je še vedno zelo nepopolno, vendar je to vseeno prava aplikativna fizična geografija.

Slika 4: Poplavna ravnica ob Dravinji pri vasi Ljubično blizu Poljčan.

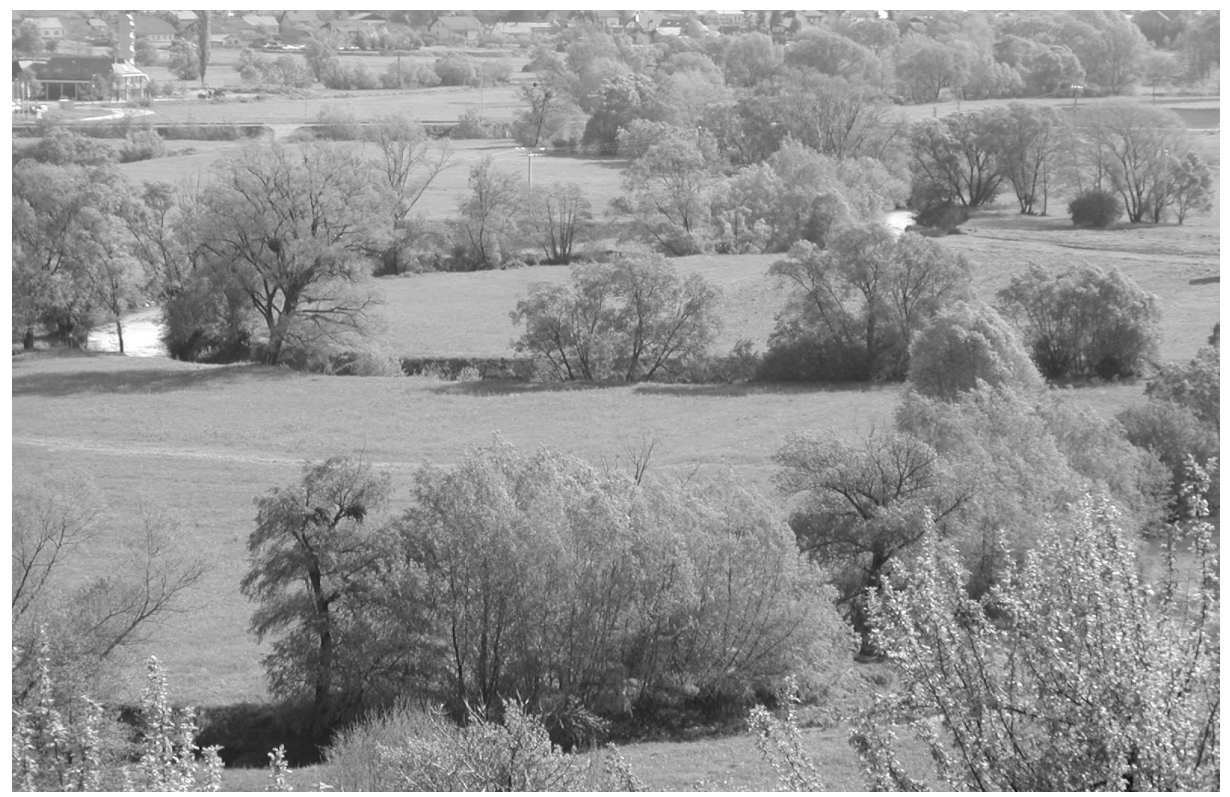

Vse to znanje in izkušnje preteklih rodov je na različne načine prisotno $\mathrm{v}$ pokrajini, mdr. $v$ načinu rabe prostora, vključno $\mathrm{z}$ upoštevanjem omejitvenih dejavnikov (npr. ravnih površin $\mathrm{v}$ dnu kraških polj in na poplavnih ravnicah niso mogli nikoli uporabljati za njive zaradi vsakoletnih poplav) in v smotrni razporeditvi dejavnosti v prostoru (npr. bivališča na obrobju kraških polj ali izven obsega rednih poplav, travniki na poplavnih območjih). Zapišemo lahko celo nekoliko drznejšo trditev, da je tudi t.i. 'slovenskost' naših slovenskih pokrajin vsaj do neke mere rezultat takšnih in podobnih prilagoditev naravnim danostim, saj se "nacionalna identiteta navezuje na določeno krajinsko podobo, ki jo gradijo izbrani krajinski vzorci in posamezne prostorske sestavine" (Kučan, 1997, 169).

Ena od pomembnih nalog aplikativne fizične geografije je odkrivanje tega védenja in njegova aplikacija v sodobni družbi, predvsem pri načrtovanju 
posegov v okolje (prostorsko planiranje) in pri osveščanju prebivalstva o prisotnosti za človeka nevarnih naravnih pojavov v pokrajini.

V zadnjih desetletjih hitrega gospodarskega in družbenega razvoja ter izrazitega 'zatišja' brez naravnih katastrof večjih razsežnosti je velik del tega znanja pri nas in tudi drugje $\mathrm{v}$ svetu izpuhtel, brez ustrezne alternative. Lep primer, kako je človek pozabil, da velike in majhne reke potrebujejo dodatni prostor za odtekanje poplavnih voda, so poplave ob reki Labi na Ceškem in v Nemčiji ter v Zgornji Avstriji avgusta 2002. Dobesedno nihče ni pričakoval, da se lahko v sedanjem času (in to sredi poletnih počitnic!) zgodi t.i. stoletna poplava. Tudi podobne poplave ob Odri in Visli julija 1999 so bile že skoraj povsem pozabljene! Pri ljudeh in v medijih je prišlo do pravega šoka predvsem zaradi poplavitve starih mest (Praga, Dresden, Magdeburg, Wittenberg, Passau), v katerih se ljudje počutimo veliko varnejše pred naravnimi nesrečami kot na podeželju., Dejstvo je, da vsa ta mesta stojijo v poplavnih ravnicah Labe in Donave in so bila v prejšnjih stoletjih že večkrat poplavljena.

Za razliko od mnogih prejšnjih naravnih nesreč ob tokratnih poplavah $\mathrm{v}$ medijih skorajda ni bilo zaslediti tožb o 'kruti naravi, ki se izživlja nad nebogljenimi ljudmi'. Skoraj soglasno so kot glavni vzrok obeh katastrof izpostavljali pretirane in nepremišljene posege $\mathrm{v}$ poplavne ravnice rek in kot na novo odkrili, da so poplavne ravnice rek prostor, ki ga reke nujno potrebujejo za odtekanje proti morju. V zvezi s temi poplavami se je veliko govorilo tudi o globalnem spreminjanju podnebja, ki zelo hitro postaja glavni kandidat za dežurnega krivca vseh bodočih vremenskih ujm. O morebitnih učinkih teh sprememb pa vemo še zelo malo in tudi to bi lahko bilo v prihodnje pomembno področje za poglobljene geografske in multidisciplinarne študije.

\section{SUBJEKTIVNO ZAZNAVANJE OGROŽENOSTI}

Poleg objektivne ogroženosti kot stvarne sestavine vsake poseljene pokrajine pa obstaja še skoraj povsem neraziskano področje ogroženosti zaradi naravnih dogodkov (nesreč) v zavesti ljudi.

Zaznavanje ogroženosti je izrazito subjektivno, vezano predvsem na neposredne izkušnje posameznika, in ni nujno v korelaciji z resničnimi nevarnostmi, ki jim je posameznik oziroma družba izpostavljena v določeni pokrajini.

Čeprav ta vidik ogroženosti v naravi ni neposredno viden, je subjektivno zaznavanja ogroženosti zaradi naravnih dogodkov/procesov (nesreč) pomembna sestavina pokrajine. Od tega je namreč neposredno odvisno prepoznavanje ter ocena tveganja in s tem tudi ravnanje posameznika ali skupin v konkretni pokrajini, od načina delovanja ob naravni nesreči do dolgoročnega načrtovanja prostorskega razvoja. Pri tem se vedno soočamo z množico neznank, saj geo- 
grafska stvarnost (kulturna pokrajina) kot rezultat součinkovanja človekovega delovanja in naravnih procesov nikoli ne temelji na popolnem (geografskem) poznavanju vseh procesov, temveč na zelo omejenih informacijah o okolju, $\mathrm{v}$ katerem ljudje živimo.

Slika 5: Hiša tik ob strugi Ljubljanice v Podpeči na Ljubljanskem barju.

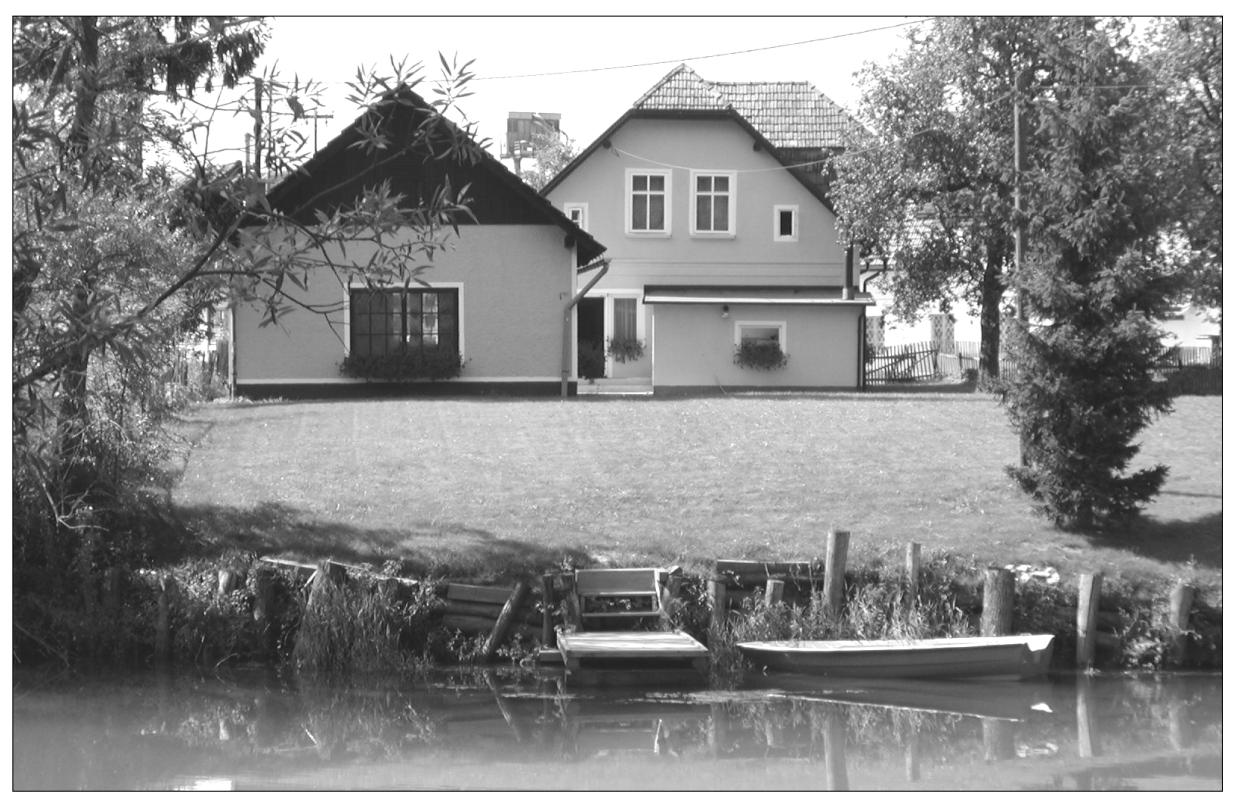

Poleg tega na naš odnos do okolja vplivajo še razni drugi subjektivni dejavniki, npr. tradicija, čustva, značaj posameznika, umetniško izražanje itd. Ta neracionalna plat človekovega delovanja v pokrajini je izjemno močno zasidrana $\mathrm{v}$ človekovi zavesti in se tudi kaže $\mathrm{v}$ današnji kulturni pokrajini, npr. kot 'lepo' v urejeni agrarni pokrajini ali kot želja po bivanju v čim bolj 'naravnem', domačem okolju brez upoštevanja tveganja zaradi naravnih procesov. Želja mnogih ljudi po lastnem domu tik ob vodi je pogosto tako močna, da povsem zakrije objektivno ogroženost zaradi poplav, včasih pa je celo tako silovita, da smo pripravljeni prepričati samega sebe, kako objektivna ogroženost $v$ našem primeru ne obstaja.

$Z$ vidika aplikacije geografije je še pomembnejše, da subjektivno (ne)zaznavanje grožnje bodočih naravnih dogodkov (nesreč) prispeva $\mathrm{k}$ vse manjšemu upoštevanju naravnih danosti pri poseganju $\mathrm{v}$ prostor in $\mathrm{s}$ tem $\mathrm{k}$ povečanju dejanske ogroženosti. Lep primer je deloma načrtno in deloma stihijsko 
širjenje Ljubljane na poplavni območji ob Gradaščici in v severnem delu Ljubljanskega barja. To območje je bilo v zadnjih 120 letih štirikrat poplavljeno: marca 1888, oktobra 1895, septembra 1926 in septembra 1933 (Vrhovnik, 1933, 134-138; Kolbezen, 1992, 217), od 'zadnje' poplave pa je res minilo skoraj 80 let. Že Cunder je pred kakšnimi 20 leti ugotovil, da se celo ljudje, ki živijo na poplavnem območju neposredno ob Gradaščici, bolj bojijo potresa kot poplave (Cunder, 1984, 38), odtlej pa se je na to območje naselilo še veliko več prebivalstva in nevarnosti poplav nihče niti ne omenja več. Kjer je bilo na poplavnem območju pred več desetletji le nekaj vasi in predmestij, živi danes več kot 30.000 ljudi. Tudi geografi smo dolžni s svojim znanjem prispevati $\mathrm{k}$ temu, da nas naslednji 'naravni dogodek' (nesreča) ne bo tako presenetil in nas našel povsem nepripravljene kot se je zgodilo ob poletnih poplavah ob Labi.

Slika 6: Hiša v dolini Male Božne v Polhograjskem hribovju je izpostavljena nevarnosti hudourniških poplav.

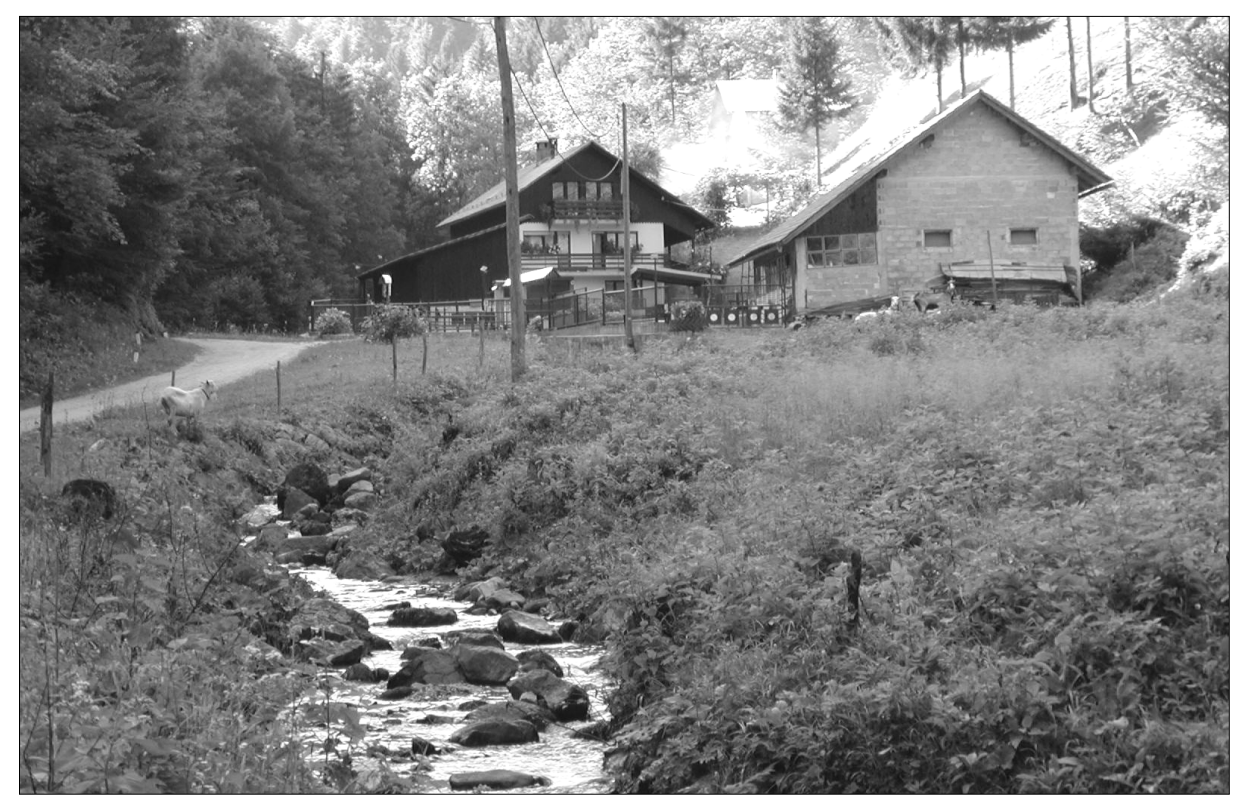

\section{SKLEP}

Geografi smo lahko kar ponosni na dosedanji prispevek naše stroke k poglobljenemu poznavanju naravnih nesreč kot sestavnega dela naravnega dogajanja, 
nekoliko manj pa $\mathrm{z}$ aplikacijo tega znanja pri načrtovanju poseganja $\mathrm{v}$ ogrožena območja. Med mnogimi prihodnjimi nalogami bi bilo potrebno izpostaviti predvsem naslednje:

1. Še naprej bomo morali strokovno in laično javnost prepričevati, da so 'neljubi' naravni dogodki/procesi (naravne nesreče) sestavni del naravnega dogajanja in jih navadno ne moremo preprečiti, lahko pa se jim uspešno prilagodimo.

2. Pretekle prilagoditve naravnim procesom so pomembna sestavina kulturne pokrajine in zato predmet geografskega preučevanja. Uporabimo jih lahko tudi za ugotavljanje objektivne (dejanske) ogroženosti.

3. Tradicionalno védenje o naravnem dogajanju in naši ogroženosti nepovratno izginja, predvsem zaradi hitrega uveljavljanja sodobnega urbanega načina življenja. Tudi geografija mora prispevati k ohranjanju tega znanja ter njegovi aplikaciji v sodobni družbi.

4. Globalno spreminjanje podnebja postaja stvarnost in geografija lahko prispeva $\mathrm{k}$ prilagajanju spremenjenim razmeram in lajšanju negativnih učinkov.

5. Zaznavanje ogroženosti je izrazito subjektivno, temelji na zelo omejenih informacijah o okolju ter drugih vplivih človekove zavesti, vendar je ta subjektivnost sestavni del geografske stvarnosti in jo je treba upoštevati.

6. Geografija lahko veliko pomaga, da subjektivno (ne)zaznavanje ogroženosti zaradi naravnih dogodkov (nesreč) ne bo povzročilo povečanja dejanske ogroženosti ljudi in njihovega premoženja v naši državi.

\section{Literatura:}

Cunder, T., 1984. Ogroženost Ljubljanskega barja po poplavah in potresih s posebnim ozirom na južni rob Ljubljane. Ljubljana, diplomska naloga, 75.

Gams, I., 1955. Snežni plazovi v Sloveniji v zimah 1950-1954. Geografski zbornik, 3, 121-219.

Gams, I., 1983. O razsežnosti in potrebnosti raziskovanja naravnih nesreč v Jugoslaviji. V: Naravne nesreče v Jugoslaviji s posebnim ozirom na metodologijo geografskega preučevanja, Ljubljana, 5-16.

Gams, I., 1996. Termalni pas v Sloveniji. Geografski vestnik, 68, 5-38.

Kolbezen, M., 1992. Velike poplave in povodnji na Slovenskem 2. Ujma, 6, 214-219.

Kučan, A., 1997. The modern social conception of Slovene space (Slovenski prostor v sodobni družbeni predstavi). Geografski zbornik, 37, 111-169.

Melik, A. in sod., 1954. Povodenj okrog Celja junija 1954. Geografski vestnik, 26, 3-58. 
Meze, D., 1966. Gornja Savinjska dolina. Nova dognanja o geomorfološkem razvoju pokrajine. Dela SAZU, razred za prirodoslovne in medicinske vede, 20, 200.

Mulej, F., 1994. Snežni plazovi, smrtne žrtve in materialna škoda. Ujma, 8, 96-101.

Naravne nesreče v Jugoslaviji s posebnim ozirom na metodologijo geografskega preučevanja. Ljubljana 1983, 148.

Naravne nesreče v Sloveniji kot naša ogroženost. Ljubljana 1983, 143.

Natek, K., 1990. Geomorfološke značilnosti usadov v Halozah. Ujma, 4, 11-15.

Natek, K., 1991. Plazovi v Gornji Savinjski dolini. Ujma, 5, 62-65.

Radinja, D., 1983. Naravne nesreče v geografski luči. V: Naravne nesreče v Jugoslaviji s posebnim ozirom na metodologijo geografskega preučevanja, Ljubljana, 17-29.

Ribarič, V., 1994. Potresi v Sloveniji. Ob stoti obletnici velikega ljubljanskega potresa. Ljubljana, Slovenska matica, 173.

Šifrer, M., 1974. Poglavitne značilnosti razvoja Škofjeloškega hribovja. Loški razgledi, 21, 11-24.

Šifrer, M., Lovrenčak F., Natek M., 1981. Geografske značilnosti poplavnih območij ob Krki pod Otočcem. Geografski zbornik, 20, 95-208.

Vrhovnik, I., 1933. Trnovska župnija v Ljubljani. Ljubljana, 447.

\section{HUMAN VULNERABILITY DUE TO NATURAL PROCESSES AS A CONSTITUENT ELEMENT OF SLOVENIAN REGIONS}

\footnotetext{
Summary

Slovenian geographers have, so far, contributed a fair amount of knowledge to the understanding of natural hazards as constituent parts of every cultural landscape, although there is still a lot to be done, especially in the application of this knowledge to the planning of human interventions into hazardous areas.

Among others, the following topics could be of great importance in the near future:

1. There is a growing need of convincing the professional and general public that 'unpleasant' natural events (natural disasters) are the expression of continuing natural processes. Due to their size and ubiquity they usually cannot be stopped or prevented by human actions but, there are many ways of more or less successful adaptation to them.
} 
2. The past adaptations to the natural processes are important structural elements of cultural landscape and, therefore, the object of geographical investigation, e. g. traditional use of flood plains for meadows, location of settlements on higher ground, avoidance of unstable slopes or paths of avalanches. The geographical interpretation of such elements can be of great importance for the determination of existing hazards and human vulnerability in particular location.

3. Traditional knowledge of natural phenomena and hazards is disappearing very rapidly, mostly due to the prevalence of urban way of life and growing alienation from the natural environment. It is necessary that geography is continuing to prevent this knowledge to become forgotten and to adapt it to the needs of modern society.

4. The global climatic changes are becoming reality of daily life. Geography could contribute to the adaptation of society to these changes and to the mitigation of negative effects.

5. The perception of vulnerability is very subjective, it is not based on the ultimate (perfect) geographical knowledge but on very limited amount of informations about the environment a person had to live in. The relations between humans and environment are also influenced by emotions, traditions, artistic creativity etc. Although these expressions of human consciousness are mostly beyond the reach of geographical methods, their implementation in the landscape is a constituent part of geographical reality and, therefore, should be considered in the study of human vulnerability, too.

6. The subjective (non)perception of vulnerability can lead to the carelessness, negligence or even denial of natural events/processes which can, under some circumstances, very rapidly change into a disaster. Geography should help to prevent that this (non)perception will result in growing risk of future events, disastrous to the people and their possessions. 